\title{
EVAPORATION CHARACTERISTICS OF ELECTRON BEAM GUN HEATED SOURCES
}

\author{
PAUL C. BAYNES and T. NAGARAJAN \\ Department of Nuclear Physics, University of Madras, A.C. College Campus, Madras 600025 , India \\ (Received April 20, 1983; in final form July 6, 1983)
}

Exact expressions for the thickness profile of thin films deposited using electron beam gun heated sources are obtained in terms of the source-substrate geometry. Calculations based on conical and cylindrical indentations show the latter to be more realistic. Self-masking effects at the source are taken into account.

\section{INTRODUCTION}

The thickness of thin films using EBG heated sources decreases with increasing angle of emission $\theta$, at a rate more rapid than $\cos ^{2} \theta .^{1,2}$ An empirical relation was proposed by Graper to describe the same. Szilagyi ${ }^{3}$ tried to explain this theoretically but failed to do so as his functions $f(r)$ and $g(r)$ depend on parameters that are not well known. Further, his assumption of a cone source implies a $\cos ^{2} \theta$ dependence in the umbral region of deposition, as will be shown in this paper. This however is not borne out by Graper's work which indicates self-masking effects being effective even at small emission angles. Hence a hollow cylindrical source has also been investigated. Further, while the emission characteristics based on the source-substrate geometry have been investigated for a number of source shapes, ${ }^{4}$ no such work has been reported for the EBG source (other than a preliminary report by $\mathrm{us}^{5}$ ).

\section{THEORY}

\subsection{Cone Source:}

Consider the source of radius $\mathrm{R}$ and height $\mathrm{H}$ to consist of a stack of rings whose radii vary from $O$ to $R$. Each ring is assumed to be an array of small area surface sources. The emission characteristic of the cone is obtained by integrating over the characteristic for the rings. From Figure 1 two regions of deposition may be identified:

(i) The Umbral (unshadowed) region where $\mathrm{x} / \mathrm{z} \leqslant \mathrm{R} / \mathrm{H}$

(ii) The Penumbral region $\mathrm{x} / \mathrm{z} \geqslant \mathrm{R} / \mathrm{H}$ where only a part of the cone emits towards the point $\mathrm{P}(\mathrm{x}, \mathrm{o}, \mathrm{z})$, i.e., $\mathrm{P}$ sees varying fractions of the rings of which the cone is composed. The fraction varies from unity at $h=H$ to zero at some cut-off height $h_{0} . h$ is the height of the ring of radius $r$, from the apex.

The emission characteristic for a ring array of small area surface sources is given by ${ }^{4}$

$$
\mathrm{T}_{\mathrm{PR}}=\mathrm{m} / \rho \pi \frac{(\mathrm{z}-\mathrm{h})^{2}\left((\mathrm{z}-\mathrm{h})^{2}+\mathrm{x}^{2}+\mathrm{r}^{2}\right)}{\left(\left((\mathrm{z}-\mathrm{h})^{2}+\mathrm{x}^{2}+\mathrm{r}^{2}\right)-4 \mathrm{x}^{2} \mathrm{r}^{2}\right)^{3 / 2}}
$$


Region $1: \mathbf{x} / \mathbf{R} \leqslant \mathrm{z} / \mathrm{H}$

The emission characteristic of the cone is

$$
T_{P C}=\int_{0}^{H} T_{P R} d h
$$

Since $h$ and $r \ll z$,

$$
\mathrm{T}_{\mathrm{PR}}=\mathrm{m} / \rho \pi \frac{\mathrm{z}^{2}}{\left(\mathrm{z}^{2}+\mathrm{x}^{2}\right)^{2}}
$$

Thus

$$
\mathrm{T}_{\mathrm{PC}}=\mathrm{m} / \rho \pi \frac{\mathrm{z}^{2}}{\left(\mathrm{z}^{2}+\mathrm{x}^{2}\right)^{2}} \mathrm{H}
$$

Region $2: x / R \geqslant z / H$

Here, one must evaluate the fraction $f_{R}$ a ring that 'sees' $P$, as well as the cut-off height $h_{o}$. Referring to Figure 2, if $S J$ is the portion of the ring that sees $P$, then

$$
\mathrm{f}_{\mathrm{R}}=\mathrm{SJ} / 2 \pi \mathrm{r}=\eta / \pi
$$

For

$$
\begin{array}{ll}
\mathrm{SJ} \leqslant 1 / 2 & \eta=\operatorname{Cos}^{-1}(1-2 \mathrm{f}) \\
\mathrm{SJ} \geqslant 1 / 2 & \eta=\pi-\operatorname{Cos}^{-1}(2 \mathrm{f}-1)
\end{array}
$$

where

$$
\mathrm{f}=\mathrm{EH} / \mathrm{EI}=\mathrm{H} / \mathrm{h}\left(\mathrm{h}-\mathrm{h}_{\mathrm{o}}\right) /\left(\mathrm{H}-\mathrm{h}_{\mathrm{o}}\right)
$$

Now when $\eta=\pi / 2, \mathrm{f}=1 / 2$ and $\mathrm{f}_{\mathrm{R}}=1 / 2$. The height of the corresponding ring

$$
\mathrm{h}_{1 / 2}=2 \mathrm{Hh}_{\mathrm{o}} /\left(\mathrm{H}+\mathrm{h}_{\mathrm{o}}\right)
$$

as easily obtained from Figure 1 .

Further, since

$$
\begin{aligned}
\tan \theta_{\mathrm{o}} & =(\mathrm{x}-\mathrm{R}) /(\mathrm{z}-\mathrm{H}) \\
& =\left(\mathrm{R}+(\mathrm{R} / \mathrm{H}) \mathrm{h}_{\mathrm{o}}\right) /\left(\mathrm{H}-\mathrm{h}_{\mathrm{o}}\right)
\end{aligned}
$$

Therefore

$$
\frac{h_{o}}{H}=\frac{H(x-R)-R(z-H)}{H(x-R)+R(z-H)}
$$




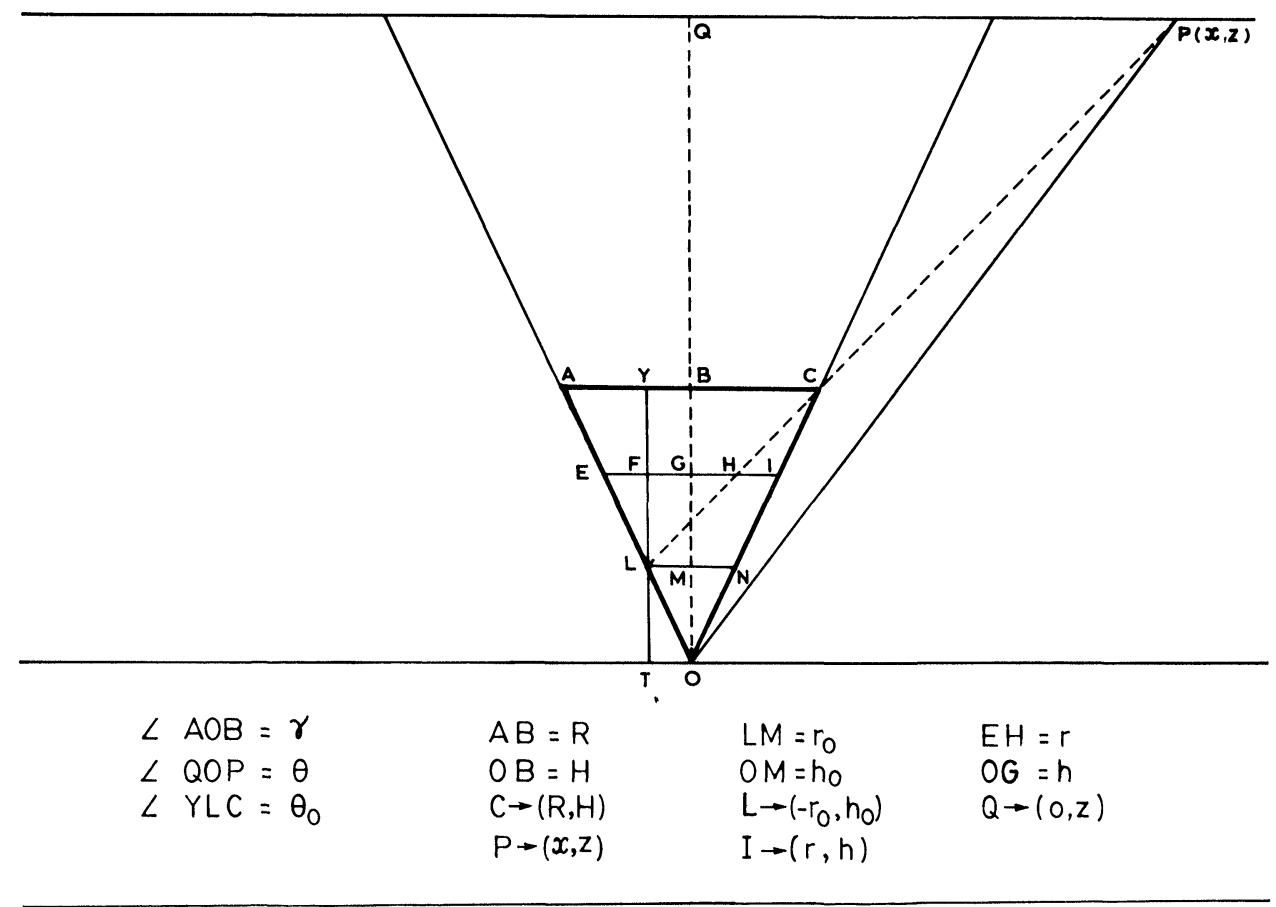

FIGURE 1 Geometry of cone source.

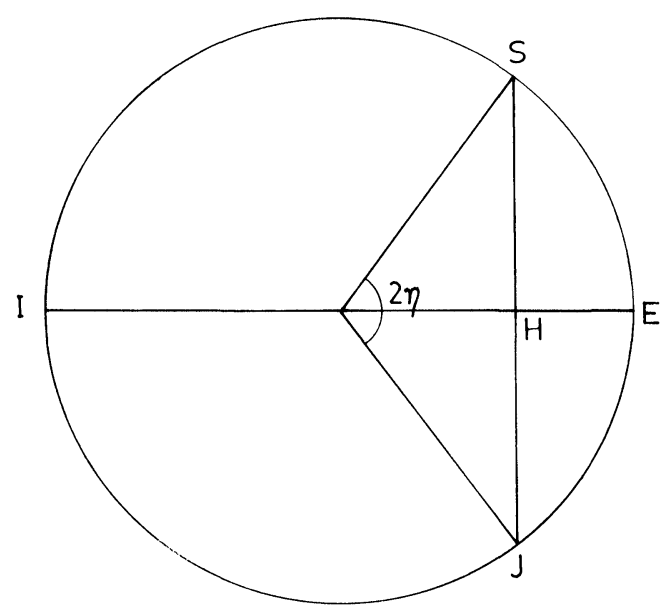

FIGURE 2 Evaluation of $f_{R}$.

Thus the thickness at point $\mathrm{P}$ is evaluated from:

$$
T_{P C}=\int_{h_{O}}^{H} f_{R} T_{P R} d h
$$

This gives 


$$
\mathrm{T}_{\mathrm{PC}}=\frac{\mathrm{m}}{\rho \pi^{2}} \frac{\mathrm{z}^{2}}{\left(\mathrm{z}^{2}+\mathrm{x}^{2}\right)^{2}}\left(\int_{\mathrm{h}_{\mathrm{O}}}^{\mathrm{h}_{1 / 2}} \operatorname{Cos}^{-1}(1-2 \mathrm{f}) \mathrm{dh}+\int_{\mathrm{h}_{1 / 2}}^{\mathrm{H}}\left(\pi-\operatorname{Cos}^{-1}(2 \mathrm{f}-1)\right) \mathrm{dh}\right)
$$

Since $\mathrm{R} \ll \mathrm{z}$ and $\sin ^{2} \theta<1$ we get,

$$
\mathrm{T}_{\mathrm{PC}}=\frac{\mathrm{m}}{\rho \pi} \frac{\mathrm{z}^{2}}{\left(\mathrm{z}^{2}+\mathrm{x}^{2}\right)^{2}}\left(\mathrm{H}-\left(\mathrm{h}_{\mathrm{O}} \mathrm{H}\right)^{1 / 2}\right)
$$

\subsection{Cylindrical source:}

As in the case of the cone, the cylinder is assumed to consist of a stack of rings on a disc base. The cylinder is characterised by a radius $\mathrm{R}$ and height $\mathrm{H}$. Referring to Figure 3 one can identify three regions $0<\theta<\alpha, \alpha<\theta<\delta$ and $\delta<\theta<\pi / 2 . \alpha$ defines the region in which no self-shadowing occurs. In the second region part of the base and part of the side contribute. In the third region varying fractions of the side only contribute towards $T_{P}$.

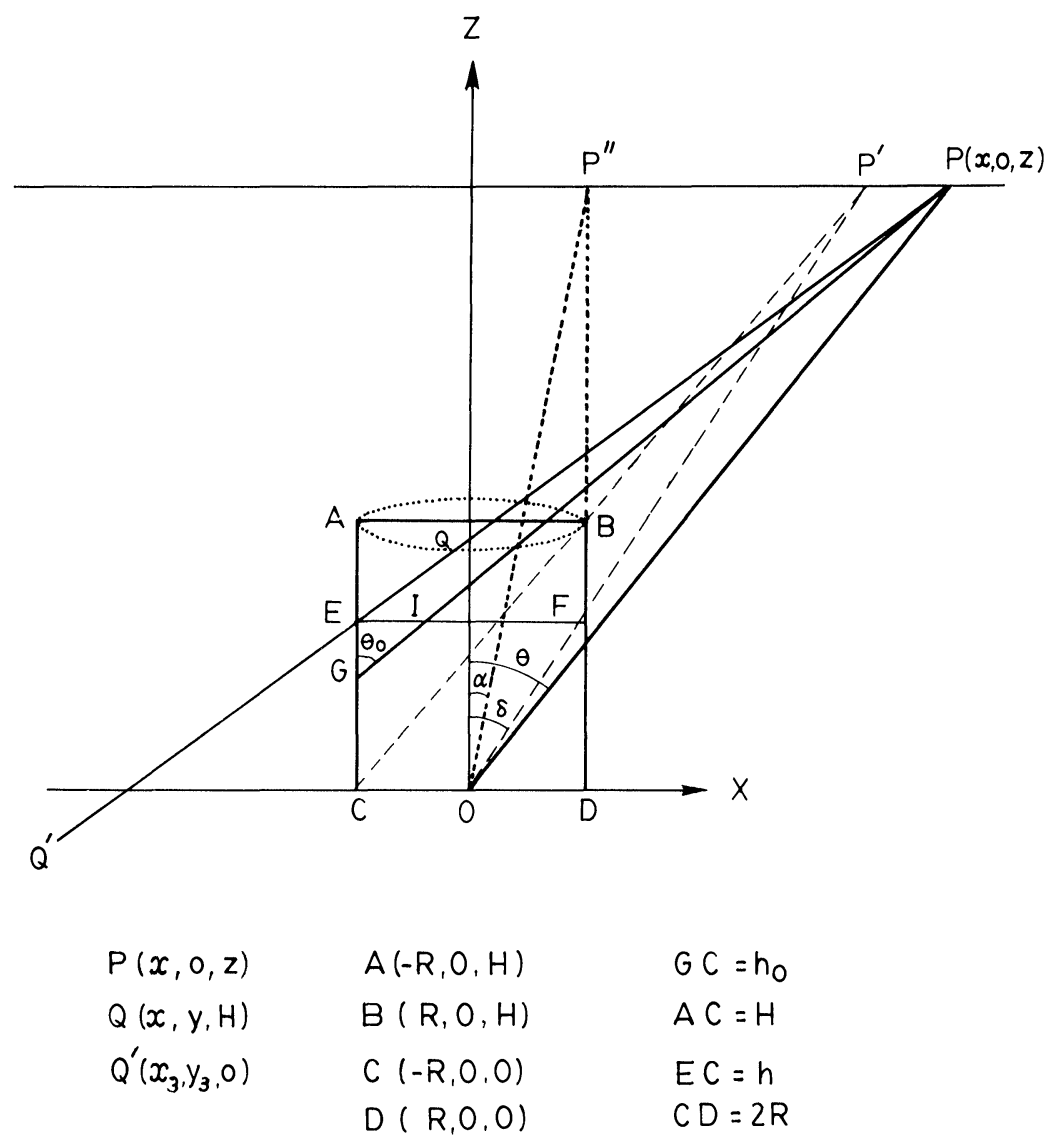

FIGURE 3 Geometry of cylindrical source. 
Thus if $C_{R}$ and $C_{B}$ are the emission characteristics of the ring and base and $f_{R}, f_{B}$ the fractions of the ring and base that emit towards the point $\mathrm{P}(\mathrm{x}, \mathrm{o}, \mathrm{z})$ we have:

$$
\begin{aligned}
T_{P} & =\int_{o}^{H} C_{R} d h+C_{B} \quad \text { in region (1) } \\
& =\int_{0}^{H} f_{R} C_{R} d h+f_{B} C_{B} \quad \text { in region (2) } \\
& =\int_{h_{O}}^{H} f_{R} C_{R} d h \quad \text { in region (3) }
\end{aligned}
$$

The emission characteristic for a ring array of small area surface sources is given by "Eq. (9)" i.e.

$$
\mathrm{C}_{\mathrm{R}}=\frac{\mathrm{m}}{\rho \pi} \frac{\mathrm{z}^{2}}{\left(\mathrm{z}^{2}+\mathrm{x}^{2}\right)^{2}}
$$

The emission characteristic of the base is that of a small area surface source i.e.

$$
\mathrm{C}_{\mathrm{B}}=\frac{\mathrm{m}}{\rho \pi} \frac{\mathrm{z}^{2}}{\left(\mathrm{z}^{2}+\mathrm{x}^{2}\right)^{2}}
$$

Region (1) $0<\theta<\alpha$. Using "Eqs (9 and 10)" in (8) we have

$$
\mathrm{T}_{\mathrm{P}}=\frac{\mathrm{m}}{\rho \pi} \frac{\mathrm{z}^{2}}{\left(\mathrm{z}^{2}+\mathrm{x}^{2}\right)^{2}}(\mathrm{H}+1)
$$

Region (2) $\alpha<\theta<\delta$. We must first evaluate $\mathrm{f}_{\mathrm{R}}, \mathrm{f}_{\mathrm{B}}$ and $\mathrm{h}_{\mathrm{o}}$. The expressions obtained for $f_{\mathrm{R}}$ earlier "(Eq. 5)" are valid for this case also. When $\eta=\pi / 2$, the emitting fraction of the ring is also $1 / 2$. i.e.

$$
f_{R}=f=1 / 2 .
$$

From Figure 3

$$
f=\left(h-h_{o}\right) /\left(H-h_{0}\right)
$$

and

$$
\mathrm{h}_{1 / 2}=\left(\mathrm{H}+\mathrm{h}_{\mathrm{o}}\right) / 2
$$

Further since

$$
\begin{aligned}
\tan \theta_{0} & =2 R /\left(H-h_{o}\right) \\
& =(x+R) /\left(z-h_{o}\right)
\end{aligned}
$$


we have

$$
h_{o}=\frac{(x+R)}{(x-R)} H-\frac{2 R z}{(x-R)}
$$

To evaluate $f_{B}$. This is easily done once the area of intersection of the locus of $\mathrm{Q}^{\prime}$ which is the projection of PQ on the XY plane, as Q is moved on the upper surface of the cylinder, keeping P fixed (Figure 4) with the basal plane of the cylinder is known. The locus turns out to be a circle of radius $\mathrm{RB}$ centred at $(-\mathrm{A}, \mathrm{O})$ where

$$
\mathrm{A}=\mathrm{xH} /(\mathrm{z}-\mathrm{H}) \text { and } \mathrm{B}=\mathrm{z} /(\mathrm{z}-\mathrm{H})
$$

Referring to Figure 5, the area of intersection is

$$
\begin{aligned}
A & =A_{1}+A_{2} \\
& =2 \int_{T J}^{T L} y d x+2 \int_{O K}^{O L} y d x
\end{aligned}
$$

where $\mathrm{T} \rightarrow(-\mathrm{A}, \mathrm{O}), \mathrm{O} \rightarrow(\mathrm{O}, \mathrm{O}), \mathrm{L} \rightarrow\left(\mathrm{x}_{\mathrm{i}}, \mathrm{O}\right) \mathrm{J} \rightarrow(-(\mathrm{A}-\mathrm{RB}), \mathrm{O})$ and $\mathrm{K} \rightarrow(-\mathrm{R}, \mathrm{O})$.

$\mathbf{x}_{\mathrm{i}}$ is the abscissa of the points of intersection of the two circles. One thus obtains:

$$
A=R^{2}\left(-B^{2} \operatorname{Sin}^{-1}\left(\left(x_{i}+A\right) / R B\right)+\operatorname{Sin}^{-1}\left(x_{i} / R\right)+\pi / 2\left(B^{2}+1\right)\right)
$$

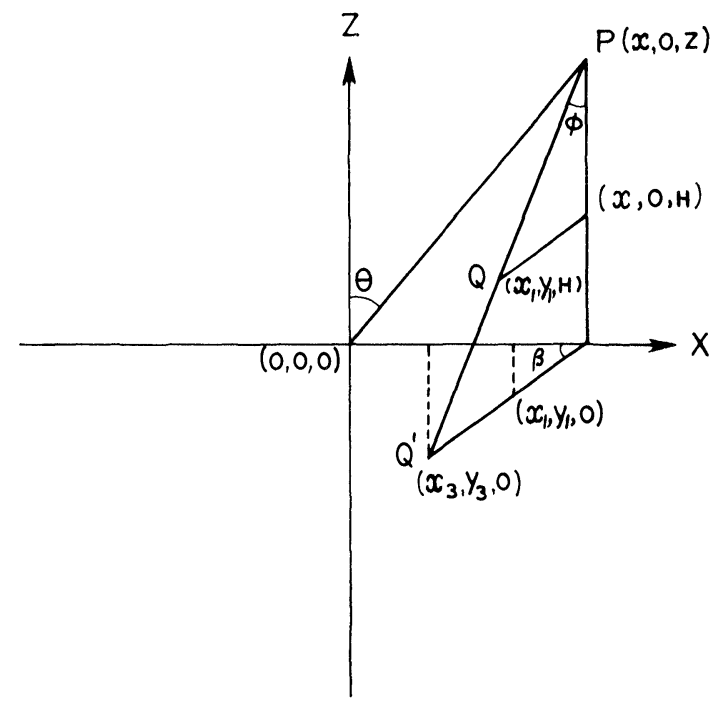

FIGURE 4 Evaluation of the locus of Q'. 


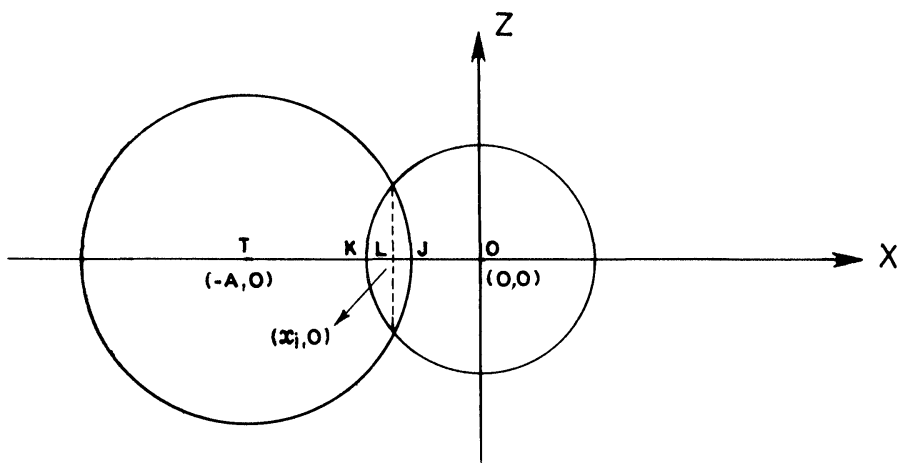

FIGURE 5 Evaluation of $\mathrm{f}_{B}$.

with

$$
x_{i}=-\left(\frac{R\left(1-B^{2}\right)+A^{2}}{2 A}\right)
$$

Using "Eq. 17)"

$$
f_{B}=A / \pi R^{2}
$$

Thus the emission from the fraction towards $\mathrm{P}$ is

$$
\mathrm{T}_{\mathrm{PB}}=\mathrm{f}_{\mathrm{B}} \mathrm{C}_{\mathrm{B}}
$$

ie.

$$
\mathrm{T}_{\mathrm{PB}}=\frac{\mathrm{m}}{\rho \pi^{2}} \frac{\mathrm{z}^{2}}{\left(\mathrm{z}^{2}+\mathrm{x}^{2}\right)^{2}}\left(\operatorname{Sin}^{-1}\left(\mathrm{x}_{\mathrm{i}} / \mathrm{R}\right)-\mathrm{R}^{2} \operatorname{Sin}^{-1}\left(\left(\mathrm{x}_{\mathrm{i}}+\mathrm{A}\right) / \mathrm{RB}\right)+\pi / 2\left(\mathrm{~B}^{2}+1\right)\right)
$$

Similarly the emission from the rings gives

$$
\begin{aligned}
\mathrm{T}_{\mathrm{PR}}= & \frac{\mathrm{m}}{\rho \pi^{2}} \frac{\mathrm{z}^{2}}{\left(\mathrm{z}^{2}+\mathrm{x}^{2}\right)^{2}} \frac{\left(\mathrm{H}-\mathrm{h}_{\mathrm{o}}\right)}{2}\left(\pi+\frac{\left(\mathrm{H}+\mathrm{h}_{\mathrm{o}}\right)}{\left(\mathrm{H}-\mathrm{h}_{\mathrm{o}}\right)}\right. \\
& \left.\operatorname{Cos}^{-1}\left(\frac{\left(\mathrm{H}+\mathrm{h}_{\mathrm{o}}\right)}{\left(\mathrm{H}-\mathrm{h}_{\mathrm{o}}\right)}\right)-\frac{-2\left(-\mathrm{h}_{\mathrm{o}} \mathrm{H}\right)^{1 / 2}}{\left(\mathrm{H}-\mathrm{h}_{\mathrm{o}}\right)}\right)
\end{aligned}
$$

Using “Eqs. (20 and 21)", the thickness of the deposit at P is

$$
\mathrm{T}_{\mathrm{P}}=\mathrm{T}_{\mathrm{PR}}+\mathrm{T}_{\mathrm{PB}}
$$


It should be noted that in this region, $-\infty<h_{o}<0$, implying that $h_{o}$ is not the cut-off height, the latter being equal to zero.

Region (3) $\delta<\theta<\pi / 2$. As before using "Eqs. (5, 10,13 and 14)" in (9), we get

$$
\mathrm{T}_{\mathrm{P}}=\frac{\mathrm{m}}{\rho \pi} \frac{\mathrm{z}^{2}}{\left(\mathrm{z}^{2}+\mathrm{x}^{2}\right)^{2}}\left(\frac{\left(\mathrm{H}-\mathrm{h}_{\mathrm{o}}\right)}{2}\right)
$$

All the above expressions have been obtained for deposition onto a planar substrate. If however the substrate is spherical and concentric with the source, the substitution $\mathrm{z}=\xi$ $\operatorname{Cos} \theta$ and $\operatorname{Cos} \theta=\mathrm{z} /\left(\mathrm{z}^{2}+\mathrm{x}^{2}\right)^{1 / 2}$ must be made. $\xi$ is the radius of the sphere.

The angles $\alpha$ and $\delta$ are given by

$$
\begin{aligned}
\alpha= & \tan ^{-1}(\mathrm{R} / \mathrm{z}) \\
& \tan ^{-1}(2 \mathrm{R} / \mathrm{H}-\mathrm{R} / \mathrm{z})
\end{aligned}
$$

for planar substrates, and

$$
\begin{gathered}
\alpha=\tan ^{-1} \frac{\mathrm{R} /}{\left(1-(\mathrm{R} /)^{2}\right)^{1 / 2}} \\
\delta=2 \tan ^{-1}\left(\frac{-\xi \operatorname{Cos} \gamma+((\xi+\mathrm{R} \operatorname{Cos} \gamma)(\xi-\mathrm{R} \operatorname{Cos} \gamma))^{1 / 2}}{\xi \operatorname{Sin} \gamma+\mathrm{R} \operatorname{Cos} \gamma}\right)
\end{gathered}
$$

for spherical substrates. When $\xi \gg \mathrm{R}$ and $\mathrm{H}$, the same values are obtained from "Eqs. (24 and 25)" for $\alpha$ and $\delta$.

\section{RESULTS AND DISCUSSION}

Polar plots of Graper's experimental data and his empirical equation are shown in Figures $(6,7,8)$ along with typical curves obtained on the cone source and cylindrical source models. From Graper's work we note that the thickness profile is smooth and has a greater than $\cos ^{2} \theta$ dependence on the emission angle. Further, the $\cos ^{2} \theta$ region if it exists, should be very close to $\theta=0$. i.e., self-masking effects at the source are effective over the whole region. The cone source model however shows a large region of $\cos ^{2} \theta$ dependence, implying that no self-masking effects occur, in this region. There is a sharp transition to the shadowed region of deposition. The curve in no way resembles the experimentally obtained profile. On the other hand, all the properties of the experimental curve are reproduced by the cylindrical source model. For example, the data for deposition at $105 \AA / \mathrm{S}$ fit well with $\mathrm{R}=0.4 \mathrm{~cm}$ and $\mathrm{H}=0.3 \mathrm{~cm}$.

\section{CONCLUSION}

Exact expressions for the thickness profile of EBG heated sources are obtained assuming hollow conical and cylindrical sources. The latter reproduce experimental results very well. 


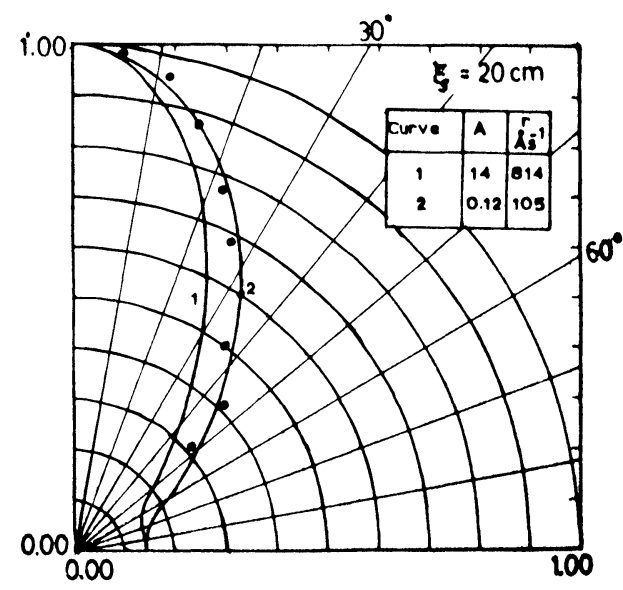

FIGURE 6 Polar Plot of Graper's result. ${ }^{1}$

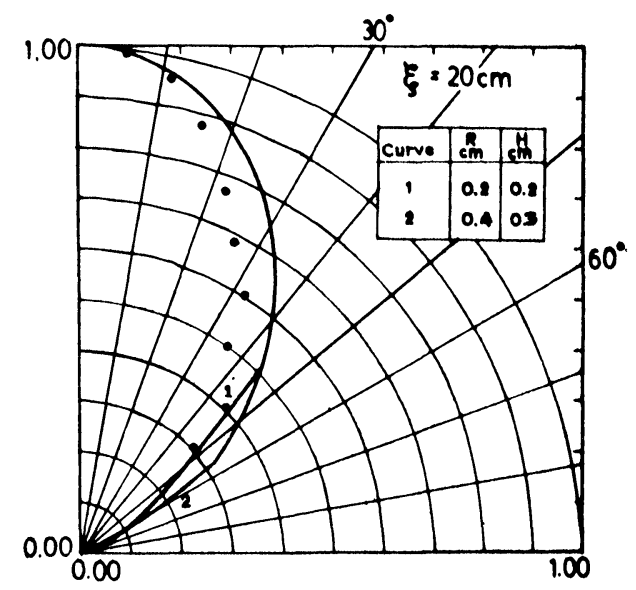

FIGURE 7 Polar Plot of the evaporation characteristics for a cone source.

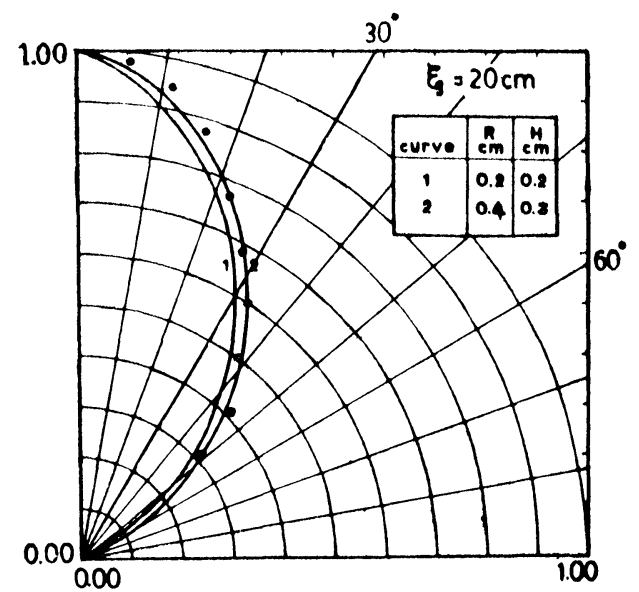

FIGURE 8 Polar Plot of the evaporation characteristics for a cylindrical source.

\section{REFERENCES}

1. E.B. Graper, "Distribution and apparent source geometry of electron-beam heated evaporation sources" J. Vac. Sci. Technol. 10, 100 (1973).

2. R. Hill, "Evaporated aluminium films: a review of techniques and improvements" (Airco Temescal, Berkeley, Calif., 1971).

3. M. Szilagyi, "Model for describing emission characteristics of electron-beam evaporation sources" Electrocomp. Sci. and Technol. 6, 9 (1979).

4. L. Holland, Vacuum Deposition of Thin Films Chapman and Hall, London, (1970) p. 153.

5. Paul C. Baynes and T. Nagarajan, "Evaporation characteristics of electron beam gun heated sources" Nucl. Phys. and Solid State Phys. (India) 24C, 565 (1981). 

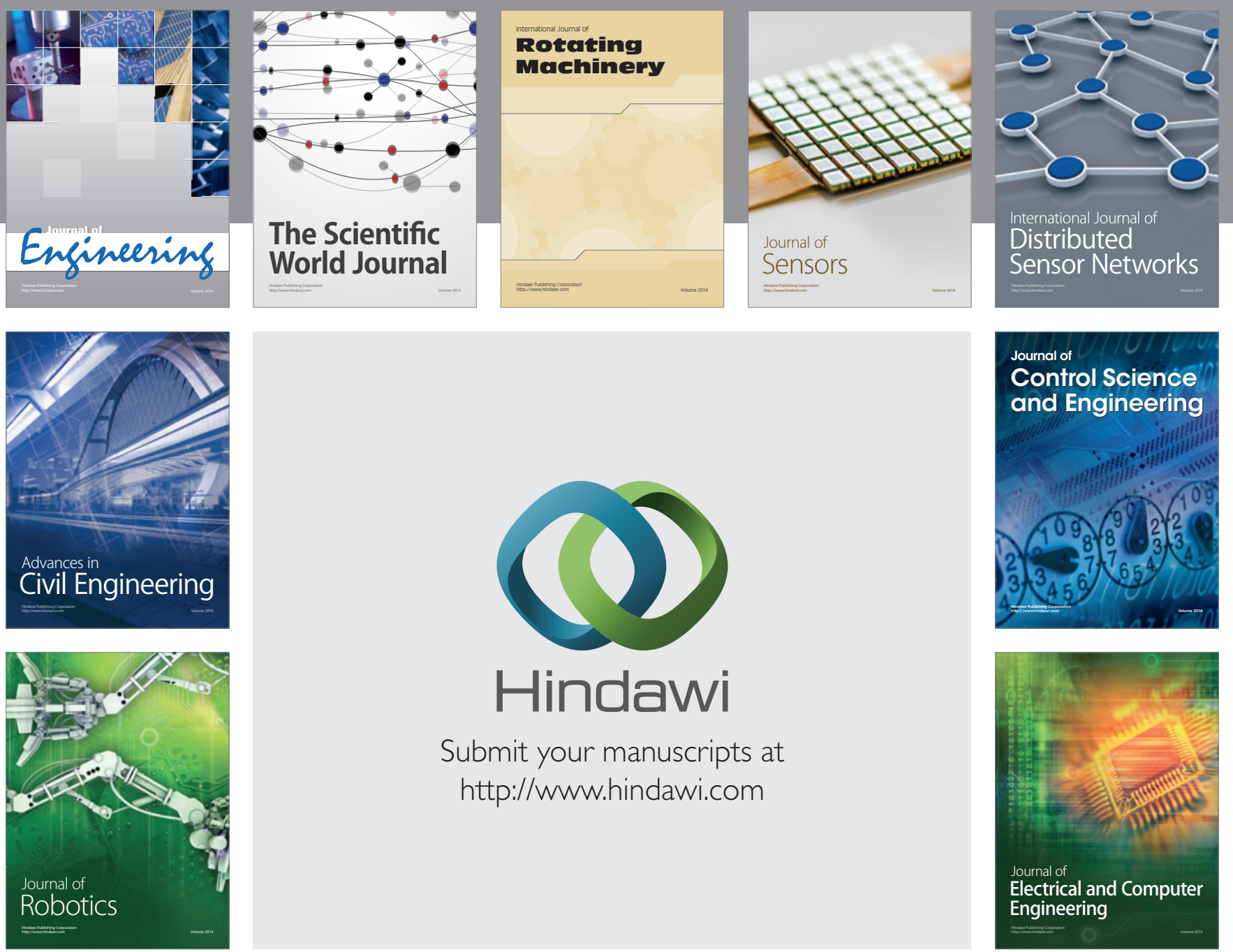

Submit your manuscripts at

http://www.hindawi.com
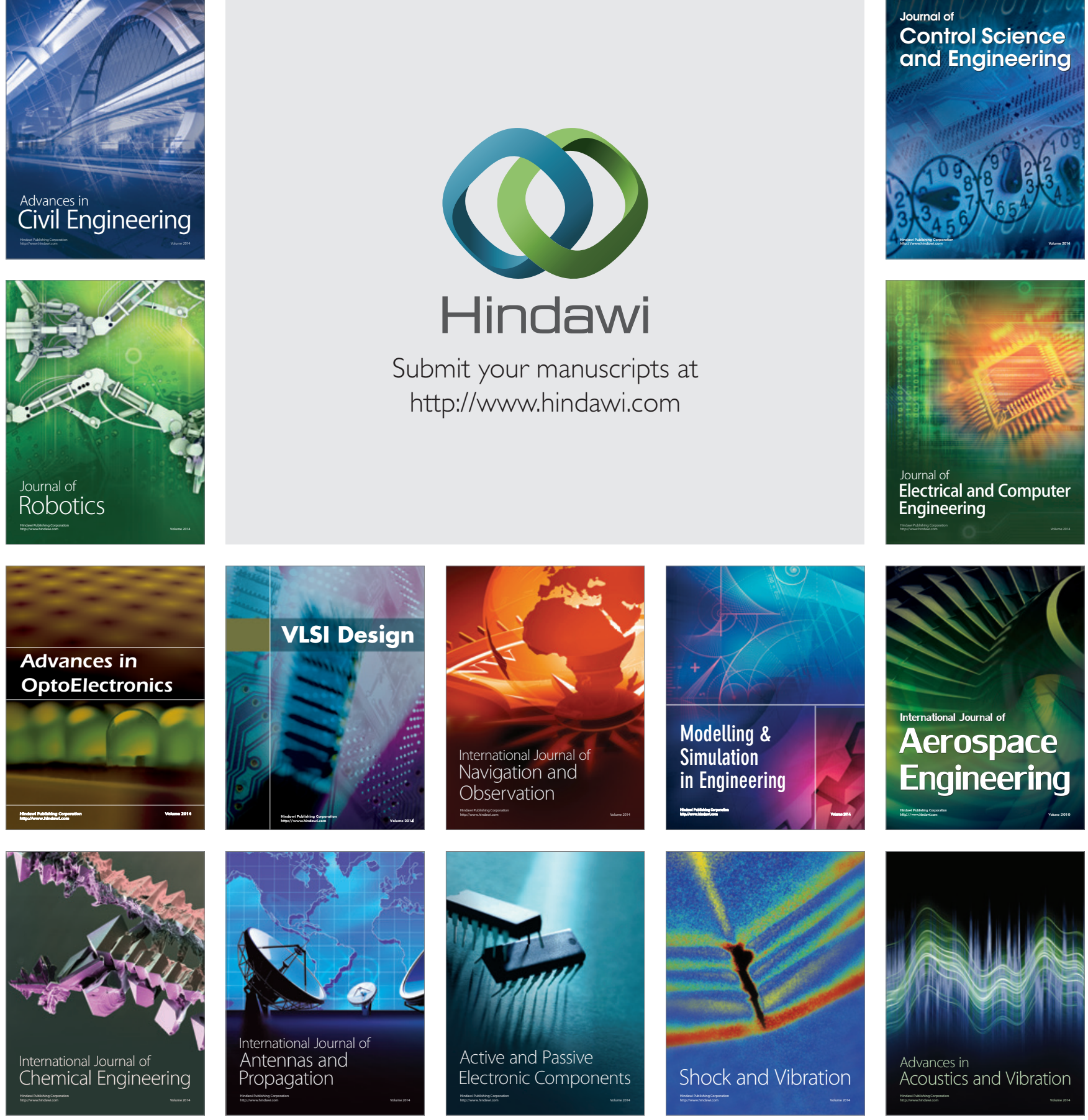